\title{
Ovaryan Endometrioma Olgularında Laparoskopik Kist Eksizyonu ile Laparoskopik Fenestrasyon, Drenaj Ve Argon Beam Coagulator Ile Vaporizasyonun Ovaryan Rezerv Üzerine Etkileri
}

\author{
The Effect of Laparoscopic Cystectomy and Vaporization With Argon Beam Coagulator on Ovarian Reserve
}

Șerife Esra Çetinkaya, Rușen Aytaç

Amaç: Endometrioma tedavisinde medikal tedavinin tek bașına yeterli ve yerinin olmadığı, tedavide altın standartın cerrahi olduğu konusunda fikir birliği mevcuttur. Laparoskopik yaklașım tercih edilen cerrahi tekniktir. Bununla beraber cerrahi ile özellikle de kistektomi ile over dokusuna ve rezervine zarar verilebilmektedir. Bu çalıșmada laparoskopik endometrioma eksizyonu ve laparosopik endometrioma fenestrasyon, drenaj ve argon beam coagulator ile koagulasyonunun ovaryan rezerv testleri üzerine etkileri olup olmadığının araștırılması amaçlanmıștır.

Gereç ve yöntem: Çalıșma Ankara Üniversitesi Tıp Fakültesi Kadın Hastalıkları ve Doğum Anabilim Dalı́nda ovaryan endometrioma nedeni ile laparoskopi yapılan 20 - 37 yas arası hastalarda gerçeklestirildi. Hastalara laparoskopik kistektomi $(n=7)$ veya laparoskopik fenestrasyon, drenaj ve argon beam coagulator ile vaporizasyon $(n=4)$ yapıldı. Tüm hastalarda preoperatif 1 ay önce ve postoperatif 1 ay sonra 3.gün $\mathrm{FSH}$, estradiol düzeyleri ve klomifen sitrat sonrası 10.gün FSH düzeyleri ile over rezervi değerlendirildi.

Bulgular: Calıșmamızda tüm hastalar birlikte değerlendirildiğinde bazal FSH ve estradiol düzeyleri arasında, klomifen sitrat testi ile 10.gün ve 3+10.gün FSH düzeyleri arasında preoperatif ve postoperatif olarak fark bulunmamıștır. Laparoskopik kist eksizyonu ve ablasyonu yapılan gruplarda ayrı ayrı yine preoperatif ve postoperatif over rezerv testleri arasında fark bulunmamıștır. Daha önce laparotomik bilateral ovaryan endometrioma eksizyonu öyküsü olan 1 hasta haricinde tüm hastalarda over rezerv testleri normal olarak saptanmıștır.

Sonuç: Bu pilot çalıșmada, endometrioma olgularında L/S kistektomi ve L/S fenestrasyon, drenaj ve argon beam coagulator ile vaporizasyonun bazal FSH, estradiol ve klomifen sitrat üzerine etkisi olmadığı görülmüstür. Argon beam koagulatörün endometrioma cerrahisinde kist duvarının ablasyonunda kullanılabilirliğinin ve cerrahinin over dokusu üzerine etkisinin araștırıldığı, her iki tekniğin duyarlı over rezervi belirteçleri ile karșılaștırıldığı randomize prospektif çalıșmalara gereksinim vardır.

Anahtar Sözcükler: Endometrioma, kistektomi, ablasyon, argon beam coagulator, over rezervi

Aim: There is general agreement that medical treatment alone is inadequate and surgery is the gold standart in the treatment of ovarian endometriomas. Laparoscopy is the preferred surgical method. However, it has been proposed that surgery, especially cystectomy may damage ovarian tissue and reserve. In this study, we aimed to determine whether laparoscopic excision and laparoscopic fenestration, drainage and vaporization using the argon beam coagulator have any effect on ovarian reserve tests.

Materials and methods: Patients who underwent laparoscopy between $20-37$ years of age with endometriomas at the Ankara University Medical Faculty, Department of Obstetrics and Gynecology were included in the study. Laparoscopic cystectomy $(n=7)$ or laparoscopic fenestration, drainage and vaporization with the argon beam coagulator $(n=4)$ was performed. Ovarian reserve was measured by day $3 \mathrm{FSH}$, estradiol levels and day $10 \mathrm{FSH}$ levels after clomiphene citrate challenge test in all patients and preoperative and postoperative levels were compared.

Results: There were no significant differences in basal FSH, estradiol levels and day 10/day 10+3 FSH levels preoperatively and postoperatively in all patients. The ovarian reserve tests were also similar preoperatively and postoperatively in the laparoscopic cystectomy or vaporization groups. Ovarian reserve tests were found to be normal in all patients but one with a history of laparotomic excision of bilateral endometriomas.

Conclusion: In this preliminary study, no effect on basal FSH, estradiol and clomiphene citrate challenge test with both surgical techniques has been observed. A prospective, randomized study is needed to make a definitive conclusion regarding the effect of cystectomy and ablation on ovarian reserve and the use of argon beam coagulator in endometrioma surgery.

Key Words: Endometrioma, kistektomi, ablation, argon beam coagulator, ovarian reserve 
Endometriozis uterus dışında fonksiyonel endometrial gland ve stromanin varlığ1 olarak tanımlanan, üreme çağındaki kadınlarda sık görülen bir jinekolojik problemdir. Prevalansı genel popülasyonda $\% 10$, subfertilitesi olan kadinlarda \% 25-40 olarak bildirilmektedir (1). Endometrioma, overde endometriyal gland ve stroma ile döşeli kist oluşumudur ve endometriozisi olan kadınların yaklaşık \% 17 44'ünde görülmektedir (2). Ciddi ağrı sebebi olmasının yanı sira infertiliteye yol açmakta, over rezervinin ve ovaryan stimülasyona yanitın azalmasina neden olmaktadir (3, 4). Endometrioma tedavisi cerrahidir. Kistektomi (kist duvarının soyulması ve/veya eksizyonu) ve fenestrasyon, drenaj, kist duvarının ablasyonu temel tekniklerdir ya da her iki tekniğin kombinasyonunu kullananlar mevcuttur (5). Ancak, hangi tekniğin endometrioma tedavisinde en uygun seçenek olduğu konusu hala tartışmalıdır (5-8). Kistektomi ile endometrioma ve ağr1 rekürrensi daha düşük ve gebelik sonuçları daha iyi bulunduğu için genel olarak tercih edilen yöntem olmuştur $(7,9)$. Bununla beraber, ovaryan doku kaybina, over rezervinin ve ovulasyon indüksiyonuna over yanıtının azalmasina neden olduğunun gösterilmesi (4, 8-12), bu nedenle de fonksiyonel over dokusunu koruma kayg1sı ilgiyi fenestrasyon, drenaj ve ablasyona yöneltmiştir (13-15).

Argon beam coagulator (ABC), laparoskopik cerrahide kullanılan bir elektriksel enerji kaynağıdır. Bir çeşit ünipolar koterdir; ancak, elektronlar dokuya dokunmadan ünipolar elektrod vasitasıyla argon gazı aracıllı̆̆ ile taşınmaktadır. $\mathrm{Bu}$ teknikle, duman oluşmamakta, aynı zamanda gazın akışının oluşturduğu etkiyle, kan veya irrigasyon sıvısı gibi sıvılar uzaklaştırılarak elektrik enerjisi doğrudan ka- nama alanlarına ve koagule edilmek istenen alanlara yönlendirilebilmektedir. Çok çeşitli cerrahilerde kullanım alanı bulmuştur; kanamanın fazla olduğu presakral nörektomi, pulmoner, hepatik, renal/mesane, kolorektal cerrahilerde, tümör cerrahilerinde, myomektomide etkilidir. Özellikle enteroliz ve adezyolizde, doku koagulasyon derinliği 2-3 mm ile sinırlı olduğu için, parenkim hasarının az, etkili ve güvenli olduğu bildirilmektedir (16-26).

$\mathrm{Bu}$ pilot çalışmada, ovaryan endometrioma olgularında laparoskopik kist eksizyonu ile laparoskopik fenestrasyon, drenaj ve $\mathrm{ABC}$ ile vaporizasyonun ovaryan rezerv üzerine etkilerini 3.gün FSH, estradiol ve klomifen sitrat testi (CCCT) ile araştırılması amaçlanmiştır.

\section{GEREÇ VE YÖNTEM}

$\mathrm{Bu}$ çalışma Ankara Üniversitesi Tıp Fakültesi Kadın Hastalıkları ve Doğum Anabilim Dalı'nda ovaryan endometrioma nedeni ile laparoskopi yapılan 13 hastada gerçekleştirildi. Çalışmaya endometrioma saptanan 20 - 37 yaş arası hastalar dahil edildi. Otuzyedi yaş üzeri ve son altı ay içinde hormonal tedavi alan hastalar çalışma dışı birakıld1. Endometrioma tanisi preoperatif olarak öykü, jinekolojik muayene ve transvajinal veya transabdominal ultrasonografi ile kondu. Ultrasonografi siklusun proliferatif fazında yapıldı. İki hasta intraoperatif olarak basit seröz kist saptanması nedeni ile çalışma dışı bırakıldı. Hastalara laparoskopik kistektomi $(n=7)$ veya laparoskopik fenestrasyon, drenaj ve argon beam coagulator ile vaporizasyon $(\mathrm{n}=4)$ yapild1.

Tüm operasyonlar genel anestezi altında umbilikus altı, her iki inguinal bölge ve gereğinde suprapubik insizyonlarla gerçekleştirildi. Tüm pelvik ve peritoneal organların inspeksiyonu yapıldı. Adezyonların görüldüğü vakalarda adezyoliz keskin, künt diseksiyonlarla ve hidrodiseksiyonla gerçekleştirildi, overler tümüyle mobilize edildi. Onüç vakanın 11'inde intraoperatif endometrioma tanısı doğrulandı, 2 hastada kistin korpus luteum kisti olduğu tespit edildi. Tüm endometriomalar insizyonla drene edildi, serum fizyolojik ile irrigasyonu takiben kist yüzeyleri incelendi.

Kistektomi yapılan grupta $(n=7)$ kist kapsülü iki atravmatik forseps yard1mılla soyularak çıkarıldı. Bipolar ve unipolar koagulasyon ile hemostaz sağlandi. Over yüzeyinde ve diğer peritoneal yüzeylerdeki endometriotik odaklar da bipolar koter ile koagule edildi. Kist kapsülü histolojik incelemeye gönderildi.

Fenestrasyon, drenaj ve vaporizasyon yapilan grupta $(n=4)$ tüm kist kapsülü argon beam coagulator ile koagule edildi. Koagulasyon prob dokuya 3 mm uzaktan tutularak yapıldı. Argon gazının akış hızı 2-4 L/dk, gücü 80W olacak şekilde ayarlandi. İntraabdominal basınç dikkatli bir şekilde 15 mmHg'yı aşmamak üzere monitorize edildi. Overlere sütür konmayarak açık bırakıldı. Over yüzeyinde ve peritoneal yüzeylerdeki odaklar $40 \mathrm{~W}$ ile koagule edildi. Tüm laparoskopik işlemlerden sonra abdominal kavite serum fizyolojik ile irrige edildi, $500 \mathrm{ml}$ serum fizyolojik pelviste birakildı. Endometrioma fenestrasyonu ve drenaj1 sonrasında kist kapsülünün $\mathrm{ABC}$ ile koagulasyonu ve ligamentum latum arka yaprağındaki endometriotik odakların ABC ile koagulasyonu şekil 1-6'da gösterilmiştir. 
Tüm hastalarda preoperatif 1 ay önce ve postoperatif 1 ay sonra over rezervi değerlendirildi. Over rezervini değerlendirmek amaciyla CCCT uygulandi. Siklusun 3.gününde bazal FSH ve estradiol ölçümünü takiben 5 -

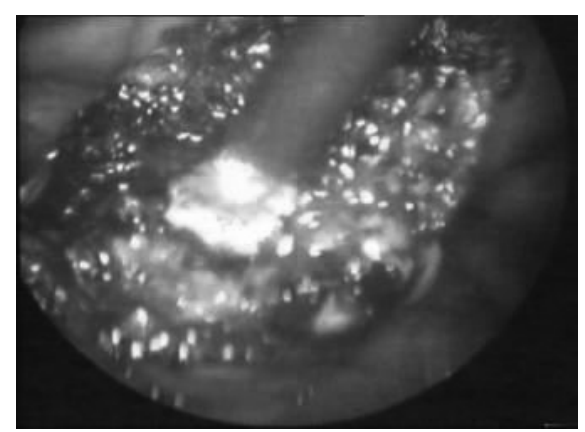

Şekil 1 9.günlerde $100 \mathrm{mg} /$ gün klomifen sitrat verildi. Onuncu günde tekrar FSH ve estradiol ölçümleri alındı. Tüm hastalarda preoperatif ve postoperatif 3.gün FSH, 3.gün estradiol, 10.gün FSH düzeyleri karşılaştırıldı. Ayrıca, 3

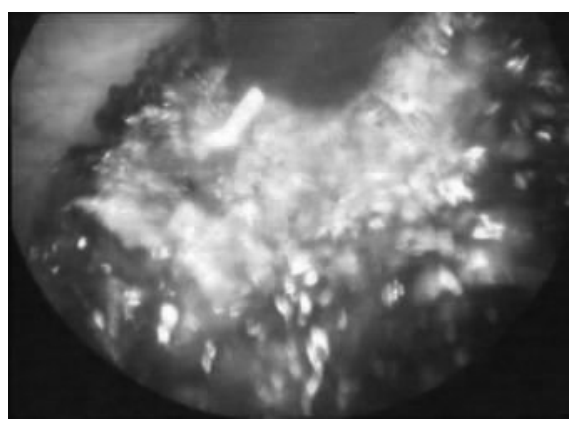

Şekil 2 ve 10.gün FSH düzeylerinin toplamı da preoperatif ve postoperatif olarak karşılaştırıldı. Karşılaştırma iki operasyon grubunda ayr1 ayr1 tekrarland. Normal kabul edilen hormon düzeyleri tablo 1'de verilmiştir.

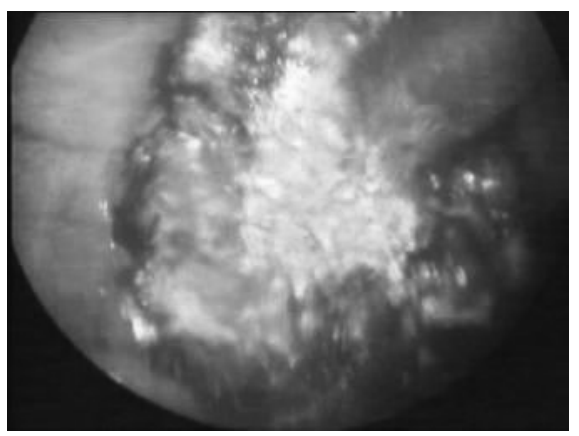

Şekil 3

Şekil 1, 2, 3: Endometrioma fenestrasyonu ve drenajı sonrasında kist kapsülünün $A B C$ ile koagulasyonu .

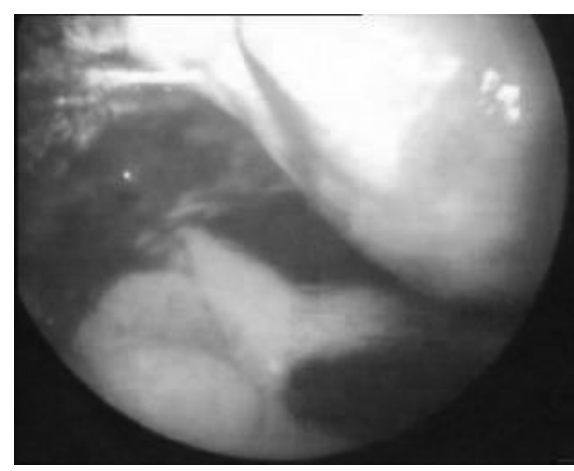

Şekil 4

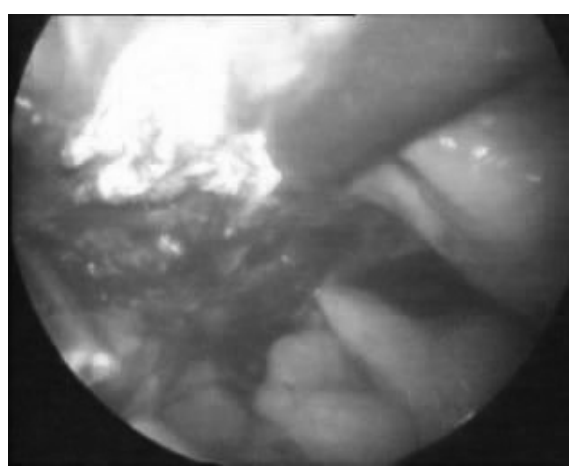

Şekil 5

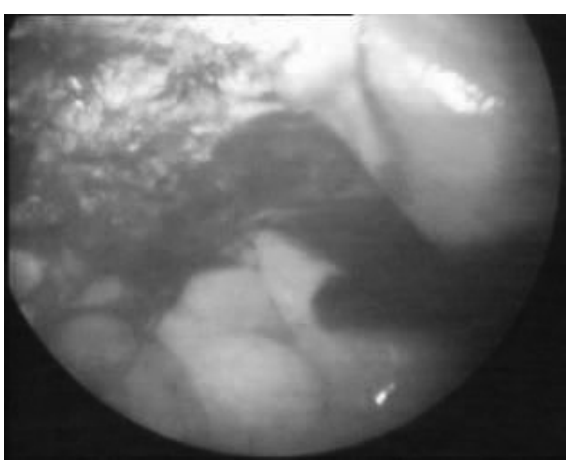

Şekil 6

Şekil 4, 5, 6: Ligamentum latum arka yaprağındaki endometriotik odakların ABC ile koagulasyonu

Tablo 1: Normal hormon düzeyleri

\begin{tabular}{|l|l|}
\hline Test & Normal \\
\hline 3.gün FSH & $<12 \mathrm{mlU} / \mathrm{mL}$ \\
\hline 3.gün estradiol & $<80 \mathrm{pg} / \mathrm{mL}$ \\
\hline CCCT ile 10.gün $\mathrm{FSH}$ & $<12 \mathrm{mIU} / \mathrm{mL}$ \\
\hline CCCT ile 3+10.gün FSH & $<26 \mathrm{mlU} / \mathrm{mL}$ \\
\hline
\end{tabular}

Tablo 2: Gruplara göre endometriomaların dağılımı ve ortalama çapları

\begin{tabular}{|l|c|c|c|c|c|}
\hline & \multirow{2}{*}{$\begin{array}{c}\text { Hasta } \\
\text { sayısı }\end{array}$} & \multicolumn{3}{|c|}{ Endometrioma sayıs (n) } & Endometrioma \\
\cline { 3 - 5 } & Unilateral & Bilateral & Toplam & (Ort \pm SD cm) \\
\hline L/S kistektomi & 7 & 4 & 4 & 12 & $3.58 \pm 1.50$ \\
\hline L/S vaporizasyon & 4 & 3 & 1 & 5 & $4.20 \pm 1.78$ \\
\hline Toplam & 11 & 7 & 5 & 17 & $3.76 \pm 1.56$ \\
\hline
\end{tabular}

Tablo 3: Hastaların preoperatif ve postoperatif 3.gün FSH düzeylerinin karşılaştırılması

\begin{tabular}{|l|c|c|c|}
\hline \multirow{2}{*}{} & \multicolumn{2}{|c|}{$\begin{array}{c}\text { 3.gün FSH düzeyleri (Ort } \pm \text { SD } \\
\mathrm{mlU} / \mathrm{mL} \text { ) }\end{array}$} & \multirow{2}{*}{$\mathrm{P}$} \\
\cline { 2 - 3 } & Preoperatif & Postoperatif & \\
\hline L/S kistektomi & $6.25 \pm 1.25$ & $7.3 \pm 4.50$ & 0.80 \\
\hline L/S vaporizasyon & $6.18 \pm 1.73$ & $4.78 \pm 2.18$ & 0.48 \\
\hline Tüm hastalar & $6.23 \pm 1.38$ & $6.40 \pm 3.90$ & 0.39 \\
\hline
\end{tabular}

Tablo 4: Hastaların preoperatif ve postoperatif 3.gün estradiol düzeylerinin karşılaştırılması

\begin{tabular}{|l|c|c|c|}
\hline \multirow{2}{*}{} & \multicolumn{2}{|c|}{3. gün estradiol düzeyleri (Ort \pm SD pg/mL) } & \multirow{2}{*}{ P } \\
\cline { 2 - 3 } & Preoperatif & Postoperatif & \\
\hline L/S kistektomi & $36.49 \pm 13.20$ & $46.44 \pm 41.53$ & 0.71 \\
\hline L/S vaporizasyon & $30.99 \pm 11.86$ & $49.8 \pm 47.3$ & 0.88 \\
\hline Tüm hastalar & $34.49 \pm 12.43$ & $47.66 \pm 41.34$ & 0.97 \\
\hline
\end{tabular}


Tablo 4.5: Hastaların CCCT sonrası preoperatif ve postoperatif 10.gün ve 3+10.gün FSH düzeylerinin karşılaştırılması

\begin{tabular}{|l|c|c|c|c|c|c|}
\hline & \multicolumn{2}{|c|}{$\begin{array}{c}\text { CCCT sonrası 10.gün FSH düzeyleri (Ort } \pm \text { SD } \\
\mathrm{mlU} / \mathrm{mL})\end{array}$} & \multirow{2}{*}{$p$} & \multicolumn{2}{|c|}{$\begin{array}{c}\text { CCCT sonrası 3+10.gün FSH düzeyleri (Ort } \\
\pm \text { SD mIU/mL) }\end{array}$} & \multicolumn{2}{c|}{$p$} \\
\cline { 2 - 3 } & Preoperatif & Postoperatif & & Preoperatif & Postoperatif \\
\hline L/S kistektomi & $8.07 \pm 3.35$ & $10.59 \pm 11.19$ & 0.90 & $14.33 \pm 4.4$ & $18 \pm 15.04$ & 0.80 \\
\hline L/S vaporizasyon & $8.22 \pm 2.04$ & $6.29 \pm 1.24$ & 0.20 & $14.42 \pm 3.33$ & $11.08 \pm 21.45$ & 0.34 \\
\hline Tüm hastalar & $8.12 \pm 2.82$ & $9.02 \pm 8.95$ & 0.39 & $14.36 \pm 3.87$ & $15.48 \pm 12.2$ & 0.29 \\
\hline
\end{tabular}

\section{BULGULAR}

Çalışmaya dahil edilen 11 hastanın 7'sine (\% 63.6) laparoskopik kistektomi, 4’üne (\% 36.4) laparoskopik ABC ile vaporizasyon uygulanmıştır. Tüm hastaların ortalama yaşı $29.7 \pm 5.81$ $(20-37)$ idi. Kistektomi grubundaki hastaların ortalama yaşı $30.4 \pm 5.28$ (21 - 37), vaporizasyon grubundakilerin ise $27.25 \pm 6.94(20-35)$ idi.

Toplam endometrioma sayıs 17 idi. Endometriomalarin 12'sine eksizyon, 5 'ine argon beam coagulator ile vaporizasyon uyguland. Ortalama endometrioma çap $3.76 \pm 1.56 \mathrm{~cm}(1-7$ $\mathrm{cm}$ ) idi (Tablo 2).

Eksizyon grubundaki hastaların preoperatif ve postoperatif 3.gün FSH düzeyleri karşılaştırıldı̆̆ında istatistiksel olarak anlamli fark izlenmedi. Preoperatif ve postoperatif ortalama 3.gün FSH düzeyleri sirasiyla $6.25 \pm 1.25$ $\mathrm{mIU} / \mathrm{mL}$ ve $7.3 \pm 4.50 \mathrm{mIU} / \mathrm{mL}$ idi $(\mathrm{p}=0.80)$.

Vaporizasyon yapilan hastaların preoperatif ve postoperatif 3.gün FSH düzeyleri arasinda fark bulunmadi. Preoperatif ve postoperatif ortalama 3.gün FSH düzeyleri sirasiyla $6.18 \pm$ $1.73 \mathrm{mIU} / \mathrm{mL}$ ve $4.78 \pm 2.18$ $\mathrm{mIU} / \mathrm{mL}$ idi $(\mathrm{p}=0.48)$.

Tüm hastalar birlikte değerlendirildiğinde preoperatif ve postoperatif 3.gün FSH düzeyleri arasında yine fark izlenmedi. Preoperatif ve postoperatif ortalama 3.gün FSH düzeyleri sırasıyla $6.23 \pm 1.38 \mathrm{mIU} / \mathrm{mL}$ ve $6.40 \pm 3.9$ $\mathrm{mIU} / \mathrm{mL}$ idi $(\mathrm{p}=0.39)$ (Tablo 3).

Kistektomi yapılan hastaların preoperatif ve postoperatif 3.gün estradiol düzeyleri arasinda fark saptanmadi; sirasiyla $36.49 \pm 13.20 \mathrm{pg} / \mathrm{mL}$ ve $46.44 \pm$ $41.53 \mathrm{pg} / \mathrm{mL}(\mathrm{p}=0.71)$ olarak bulundu. Vaporizasyon grubundaki hastala- rin preoperatif ve postoperatif estradiol düzeyleri arasinda fark izlenmedi. Preoperatif ve postoperatif ortalama 3.gün estradiol düzeyleri sirasiyla $30.99 \pm 11.86 \mathrm{pg} / \mathrm{mL}$ ve $49.8 \pm 47.3$ $\mathrm{pg} / \mathrm{mL}(\mathrm{p}=0.88)$ bulundu.

Hastalar birlikte değerlendirildiğinde preoperatif ve postoperatif 3.gün estradiol düzeyleri yine benzer bulundu. Preoperatif ve postoperatif ortalama 3.gün estradiol düzeyleri sirasiyla $34.49 \pm 12.43 \mathrm{pg} / \mathrm{mL}$ ve $47.66 \pm$ $41.34 \mathrm{pg} / \mathrm{mL}$ idi $(\mathrm{p}=0.97$ ) (Tablo 4)

Bazal hormon düzeylerini takiben klomifen sitrat testi uygulanarak 10.gün ve $3+10$ gün $\mathrm{FSH}$ düzeyleri preoperatif ve postoperatif olarak karşılaştırıldı. Eksizyon yapilan hastalarda, vaporizasyon yapilan hastalarda ve tüm hastalar birlikte değerlendirildiğinde preoperatif ve postoperatif 10.gün ve 3+10.gün FSH düzeyleri benzer bulundu (Tablo 5).

Bir hasta haricinde tüm hastaların preoperatif ve postoperatif bazal FSH, estradiol düzeyleri, klomifen sitrat sonras1 10.gün ve 3+10.gün FSH düzeyleri normal sınırlar içinde idi. L/S bilateral endometrioma eksizyonu yapılan 32 yaşında bir hastanın 4 yıl önce geçirilmiş L/T bilateral endometrioma eksizyonu öyküsü mevcuttu. $\mathrm{Bu}$ hastanin preoperatif 10.gün $\mathrm{FSH}$, postoperatif 3.gün $\mathrm{FSH}$, 10.gün ve 3+10.gün FSH düzeyleri anormal bulundu.

L/S sağ endometrioma drenaji ve vaporizasyonu $(3 \mathrm{~cm})$ yapilan 1 hastanin takibinde postoperatif 8.ayda spontan gebelik izlenmiştir; gebeliğin 7.haftasında abortus ile sonuçlanmıştir.

Kistektomi yapılan tüm hastalarda endometrioma tanısı histopatolojik olarak doğrulanmıştır.

\section{TARTIȘMA}

$\mathrm{Bu}$ pilot çalışmada, laparoskopik endometrioma eksizyonu ve laparosopik endometrioma fenestrasyon, drenaj ve $A B C$ ile koagulasyonu yapilan hastalarda preoperatif ve postoperatif bazal $\mathrm{FSH}$ ve $\mathrm{E}_{2}$ düzeyleri ve CCCT sonuçlarında fark bulunmamıştır.

Endometriomaların laparoskopik cerrahisinde hangi tekniğin en uygun seçenek olduğu konusu hala tartışmalıdır. $\mathrm{Bu}$ tartışmanın ana nedeni rekürrens oranlar1 yanı sira over dokusuna verilen zarar konusudur. Endometriomaların patogenezi ile ilgili bir görüşe göre endometrioma çoğu vakada korteksin invajinasyonu ile oluşmaktadır $(27,28)$. Bir diğer görüş ise endometriomanin kortekse invajine epitelyal inklüzyonların metaplazisi ile geliştiğidir (29). Buna göre, endometrial kapsülün over korteksine çok yakın yerleşimli olduğu ve endometriomalarda kistektominin ovaryan kortekste kayba yol açacağ1 ileri sürülmüştür (30). Hachisuga ve ark laparoskopik endometrioma eksizyonu ile folikül kaybı arasındaki ilişkiyi araştırdıkları çalışmada ise kolay soyulan endometriomaların kapsüllerinin tümünde ovaryan stroma varlığını, \% 68.9'unda 1 - 25 primordial folikül varlığını göstermişlerdir. Kistektominin over stromasına zarar verdiği ve folikül kaybina neden olduğu sonucuna varmışlardır (10).

Endometriomalarda cerrahinin over rezervine zarar verip vermediği pek çok çalışmada araştırılmıştır ve çelişkili sonuçlar elde edilmiştir. Marconi ve Canis ovaryan dokuya zarar vermeden dikkatli bir cerrahi teknikle yapıldığında laparoskopik kistektominin stimulasyona over yanıtını etkile- 